\title{
Impact of an integrative activity based on clinical practices on the teaching of basic and health care pharmacology curriculum to pharmacy students
}

\author{
Francisco Alves FARIAS-FILHO ${ }^{1}$, Lívia Gonçalves MADRUGA², Riethe Oliveira ROCHA², and Vinicius Frias CARVALHO³ \\ ${ }^{1}$ Research Division of CP Courses, Rio de Janeiro, Brazil;'P2Phamaceutical Clinical Service, University Center Augusto Motta, Rio de \\ Janeiro, Brazil; ${ }^{3}$ Laboratory of Inflammation, Oswaldo Cruz Institute, Oswaldo Cruz Foundation, Rio de Janeiro, Brazil
}

Corresponding author: Farias-Filho FA, jdezbr@yahoo.com.br

Submitted: 05-12-2020 Resubmitted: 19-02-2021 Accepted: 26-02-2021

Peer review: blind reviewers

\begin{abstract}
Objective: The aim of this work was to evaluate the impact of an integrative activity based on clinical practices in disciplines of the basic and health care curriculum of an undergraduate pharmacy school. Methods: We developed an applied an interdisciplinary methodology in basic and health care disciplines focused on hospital pharmacy practice, including Pharmacokinetics and Pharmacodynamics; Hospital Pharmacy; Pharmacology I; Pharmacology II; Toxicology; Clinical Pharmacy. The methodology used was constructed on problem-based learning (PBL) focused on the health policies integrated into pharmaceutical clinical practices. Students were encouraged to formulate hypotheses, plan experiments and to discuss their outcomes. The evaluation of the effectiveness of the methodology was performed by analyzing the following parameters: escaping of discipline and measurement of students' performance improvement. Results: We noted that students were able to reformulate their original perceptions immediately after teaching. The students significantly reduced the avoidance of Pharmacology I; Pharmacology II; Toxicology. Furthermore, the students significantly improved their school performance in all disciplines with the exception of Pharmacology I; Pharmacokinetics and Pharmacodynamics. Conclusion: The use of the integrative methodology based on clinical practice resulted in lower dropout and better academic performance. In addition, the use of this methodology promoted greater integration of students in the health care problems and clinical practices.
\end{abstract}

Keywords: drug dispensing; problem-based learning; pharmaceutical education; prescriptions analysis.

\section{Impacto de uma atividade integrativa baseada em práticas clínicas no ensino do currículo de farmacologia básica e de saúde para estudantes de farmácia}

\section{Resumo}

Objetivo: O objetivo deste trabalho foi avaliar o impacto de uma atividade integradora baseada em práticas clínicas em disciplinas do currículo básico e de saúde de uma escola de graduação em farmácia. Métodos: Desenvolvemos uma metodologia interdisciplinar aplicada nas disciplinas básicas e de saúde voltadas para a prática de farmácia hospitalar, incluindo Farmacocinética e Farmacodinâmica; Farmácia Hospitalar; Farmacologia I; Farmacologia II; Toxicologia; Farmácia Clinica. A metodologia utilizada foi construída sobre a aprendizagem baseada em problemas, focada nas políticas de saúde integradas às práticas clínicas farmacêuticas. Os alunos foram incentivados a formular hipóteses, planejar experimentos e discutir seus resultados. A avaliação da efetividade da metodologia foi realizada através da análise dos seguintes parâmetros: desistência da disciplina e mensuração da melhoria de desempenho dos alunos nas avaliações. Resultados: Observamos que os alunos foram capazes de reformular suas percepções originais imediatamente após o ensino. Os estudantes reduziram significativamente a desistência das disciplinas Farmacologia I, Farmacologia II e Toxicologia. Além disso, os alunos melhoraram significativamente o desempenho escolar em todas as disciplinas inseridas no estudo, com exceção das disciplinas de Farmacologia I e Farmacocinética e Farmacodinâmica. Conclusão: A partir desse estudo, pudemos concluir que o uso da metodologia integrativa baseada na prática clínica resultou em menor abandono e melhor desempenho acadêmico pelos discentes. Além disso, o uso dessa metodologia promoveu uma maior integração dos estudantes nos problemas de saúde e nas práticas clínicas.

Palavras-chave: dispensação de medicamentos; aprendizagem baseada em problemas; educação farmacêutica; análise de prescrições. 


\section{Introduction}

The clinical assistance in a hospital environment is known has been huge complex and demands an integration between several health professionals and strategies to guarantee patients safety. In this context, the prescriptions analysis and drug dispensing have been considered as key to the success of pharmacist in guarantee the therapeutic effectiveness associated with low risk. Problems with drug prescriptions by health professionals have been observed in the worldwide, including United Kingdom (UK), Australia and Brazil. ${ }^{1-4}$ Currently, a large proportion of hospital prescriptions are performed or analyzed by newly graduated health professionals. Prescription by newly graduated doctors is frequently suboptimal. Only in the UK, $7-10 \%$ of prescriptions written by newly graduated doctors contain errors ranging from low to high risk of death for patients ${ }^{5}$ This concern about drug prescription errors extends to other health professionals, once after receiving appropriate training these professionals, including pharmacists, may analyze and write modified prescriptions following diagnosis by a qualified clinician. For the health service, drug prescribing represents an important source of clinical risk to patients and financial cost to hospitals. ${ }^{6-7}$

In this context, some countries began to worry about the graduation training of these professionals. In the UK, the UK Medical Schools Council together to General Medical Council, health-care employers, postgraduate educators, and the British Pharmacological Society made several important recommendations as part of a plan for improved undergraduate training. Among them, a reliable and valid evaluation to be developed to enable final-year students to show that the necessary learning outcomes were met and that the new doctors have the necessary skills to start prescribing independently, which led to the development UK Prescribing Safety Assessment. ${ }^{8}$

In the University Of Melbourne, Australia, they have developed a curriculum framework for active learning and for integrating the basic and clinical disciplines of pharmacology. The University of Melbourne has incorporated the use of problem-based learning (PBL) for the teaching of pharmacology into a vertically and horizontally integrated study program, through case studies that demonstrate an approach to teaching important pharmacological concepts interactively. ${ }^{1}$ In medical programs, the use of PBL has been performed in the last 15 years. A PBL-based curriculum model that encourages self-directed learning and motivates students through the use of relevant clinical scenarios allows the student to develop other desirable skills and attributes, including knowledge acquisition, improved group collaboration, and communication ${ }^{9}$

One way to apply the PBL is through cooperative learning, which has attracted the attention of educators. In the view of instructors, the cooperative learning activities encourage students to acquire knowledge, as well as interpersonal and team skills. In addition to the fact that when the students working in small groups, their improve your ability to interact with people and maximize your learning by reaching a common goal ${ }^{10}$. Cooperative learning is a teaching strategy applied to small teams, in which each student has your own abilities at different levels. In this methodology, the instructors use several learning activities to improve the understanding of the students. Every group member has your responsibilities for learning and help teammates learn, creating an atmosphere of achievement. Cooperative learning is characterized by five common elements, including i) awareness that the contribution of each member is important for the success of the group; ii) a virtuous circle of encouragement in which each member of the group helps the other to succeed and learn; iii) acquisition of individual and group responsibility and division of tasks, besides leadership learning can also be inserted; iv) development of small group social skills involving negotiating and use of group interaction skills; v) students' reflections on group experiences. ${ }^{11}$

Having in perspective the picture in which effective prescription analyses associated to clinical care are key elements of clinical pharmacist performance, becomes a central issue the concern in how best to prepare undergraduate students to analyze prescriptions and perform hospital pharmacy practice. The aim of this study was to evaluate the effectiveness of an integrative activity based on clinical practices in disciplines of the basic and health care curriculum of an undergraduate pharmacy course in Rio de Janeiro State, Brazil. For this, we designed the study to compare the integrated teaching methods with orthodox teaching sessions on pharmacist undergraduates.

\section{Methods}

\section{Study Design}

This study was carried out with undergraduate students of pharmacy school of University Center Augusto Motta (UNISUAM) located in Rio de Janeiro, Brazil, in the period between 2015 and 2016. We planned our study after meeting with students of each discipline of basic and health care curriculum focused on hospital pharmacy practice. In this meeting, the students were aware that their attitudes were changing and they were interested to know how and why. The Brazilian Ethics Committee designed by the Ministry of Health of the Federal Government of Brazil (CAAE 61317816.1.0000.5235) approved this study.

\section{Program Content}

The pharmacy school of UNISUAM is fully accredited by the Ministry of Education and Culture (MEC) of the Federal Government of Brazil, typically on a 5-year basis. Supplementary Table 1 lists the program of pharmacy school of UNISUAM. In practice, most of the pharmacy schools' programs in Brazil are broadly similar. In the first year of this pharmacy school, the curriculum covers aspects of morphology sciences; cellular and molecular biology; fundamental chemical and molecular sciences. In the second year, then build on this to cover analytical and organic chemistry; psychology; basic microbiology and immunology; hospital pharmacy (including pharmacy practice). In the third year, the school pharmacy covers basic biochemistry, parasitology, pathology and physiology; pharmacotecnie; bromatology; pharmacokinetics and pharmacodynamics (including pharmacy practice). In the fourth year, the curriculum covers applied pharmacology and clinical pharmacy (focused on hospital pharmacy practice); medicinal chemistry; pharmaceutical ethics, management and administration; therapeutic aspects of natural products and pharmacognosy; homeopathy, pharmaceutical biochemistry, hematology, immunology, microbiology and parasitology. The final year is normally comprised of an extended research project, which must involve some form of generation, analysis, and interpretation of novel data, and some optional in-depth study of selected topics. Furthermore, the students perform some form of practical trainee of their skills in community pharmacy, hospital pharmacy, industry pharmacy and clinical analysis. In this year, the pharmacy school also covers aspects of industry pharmacy and toxicology (focused on hospital pharmacy practice). 
In this study, we used disciplines of pharmacy school for teaching basic and health care knowledge on hospital pharmacy practice. In the basic curriculum, the following disciplines were included: Pharmacokinetics and Pharmacodynamics, and Hospital Pharmacy, while in the health care curriculum was included the disciplines Pharmacology I, Pharmacology II, Toxicology, and Clinical Pharmacy. Supplementary Table 2 shows the main topics studied in these disciplines.

\section{Teaching Method}

Previously, the pharmacy school of UNISUAM used a conventional teaching methodology, which retains some boundaries between preclinical and clinical issues. From 2016, the course started to utilize an integrated curriculum with emphasis on PBL. Although either orthodox or integrated curriculum-based learning about drugs cumulatively built up throughout the course, the highlights generic aspects of drug use can be an advantage in the intermediary years.
To study the effectiveness of PBL methodology compared to the orthodox method of teaching for undergraduate pharmacy students, in 2016, we applied an interdisciplinary and integrative activity involving basic and health care disciplines focused on pharmacy practice (Supplementary Figure 1 and Table 1). The PBL methodology used focused on three thematic axes: i) health public policies; ii) pharmaceutical cares in special groups, such as elderly, newborns, pediatric and pregnant patients; iii) patient safety. These axes should involve concepts of at least three disciplines of pharmacy school used in the study. The PBL teaching method was designed to be applied in small groups ${ }^{12-13}$ as well as in large-class and group work. ${ }^{13-16}$

In our methodology, we formed a small group with six students with one of these students been a leader of the group. The students choose one central theme about one of the three axes described above, for instance the control of arterial pressure in pregnant. Then, the group submitted this theme indicating three disciplines, which could apply the topic of study to a group of three referees (professors), which evaluated if the theme was integrative and

Table 1. Steps of PBL-method used in the integrative activity

\begin{tabular}{|c|c|c|c|}
\hline Information & Problem 1 & Problem 2 & Problem 3 \\
\hline \multicolumn{4}{|c|}{ Organization of PBLs } \\
\hline Problem situation & $\begin{array}{l}\text { Analysis of the effect of public policy } \\
\text { on patient safety (Ordinance No. } 529 \text {, } \\
\text { of April 1, 2013, Brazil) in promoting a } \\
\text { culture of patient safety in the process } \\
\text { of training pharmacists in Brazil. }\end{array}$ & $\begin{array}{l}\text { Importance of the control of arterial } \\
\text { pressure in pregnant, emphasizing } \\
\text { the rational and safe use of } \\
\text { antihypertensive. }\end{array}$ & $\begin{array}{l}\text { Importance of identifying and } \\
\text { using analgesia in cancer patients, } \\
\text { emphasizing possible drug interactions } \\
\text { that can result in drug-related } \\
\text { problems, such as duplication of drugs } \\
\text { or lack of therapeutic effectiveness. }\end{array}$ \\
\hline
\end{tabular}

Groups organization

Students were organized by subject in groups of 5-6 students. At this time, the leader was chosen by the group. Each group filled out a document with the subjects they were taking or had taken. At least three of these disciplines should be involved in the integrative activity. All group members should have at least one discipline in common.

Initially, students received a manual for preparing the integrative activity that contained the rules for preparing the work. The students were advised to search national and international protocols and recent scientific articles (last 5 years) as references. The material presented was a project written in the form of a bibliographic review or field research, following the research guidelines with human beings at CONEP. The students also presented the project in poster format to the local community.

Material produced and references used

Period of work preparation The activity was carried out over an academic semester.

Project elaboration

location

The material was prepared in meetings on the university campus, chats online, and by emails exchange. The final project presented to the local community was carried out on the University campus.

Study time

At least $15 \%$ of the regular timetable for each of the classes of the disciplines involved. Class overtime has not been pre-established.

\section{Participating units}

Pharmacokinetics and

Pharmacodynamics

Hospital pharmacy

Pharmacology I

Pharmacology II

Toxicology

Clinical pharmacy

PBLs Evaluation

Students reaction

Students behavior

Results

\section{Content/skills and workload}

Present the physical and chemical processes of drugs and biological systems. Integrate pharmacokinetics and pharmacodynamics with the understanding of clinical cases. Workload: $5 \mathrm{~h}$ in person.

Present the management, administration, and legislation of hospital pharmacy, besides concepts of pharmacovigilance. Workload: 5 h in person.

Present concepts of pharmacology of autonomous and central nervous systems, cardiovascular and renal systems, and blood diseases. Workload: $10 \mathrm{~h}$ in person.

Present concepts of pharmacology of inflammation allergic diseases, lung, gastrointestinal, and endocrine systems, and antimicrobial and antineoplastic drugs. Workload: $10 \mathrm{~h}$ in person.

Develop the student's ability to identify the main toxicological indicators and mechanisms, enabling them to diagnose, monitor, and treat poisoning. Workload: $10 \mathrm{~h}$ in person.

Discuss the principles of pharmaceutical care, in addition to using knowledge to promote the safe, effective, and rational use of drugs. Workload: 10h in person.

The students demonstrated greater animation and participation in the classes after using the integrative methodology compared to the students who only took the orthodox classes.

The students showed great mobilization for the development of the work in a cooperative and integrated way. Clearly, students showed a better understanding of the topics covered, correlating them with concepts from related disciplines. The effectiveness of the integrative methodology used was assessed using two parameters: the avoidance and academic performance of disciplines 
related to one of the axes. After the approval of the theme by the referees, the group elaborated a write material about the central theme focused on the thematic axis weekly under supervision of professors, in $15 \%$ of regular time of the discipline added in the work, as described above, and in extra class without predetermined time. A group of three referees evaluated this project. At the end of the course, this small group presented the result of this research in a scientific way to a large group in classrooms of the disciplines that comprise our study, and in a ludic way to local community around the university. A group of three referees (Table 1) also evaluated these presentations. The better projects were prized with a certificated by pharmacy school as a motivational strategy. This conjunct of evaluations comprised $30 \%$ of the final grade of the student in the discipline. It is worth mentioning that before we applied this PBL-method, up 50\% of the final grade of the student, in which discipline could be through academic activities in an orthodox way, considering the academic rules of the university.

Assessment of students' avoidance of disciplines and academic performance

To assess students' escaping of disciplines, we measured the percentage of students in the second assessment compared to the number of students who started the course. To address the students' academic performance, we evaluated the approval rate in the disciplines studied.

\section{Statistical analysis}

The data were statistically analyzed by the $\chi$ 2-test (Fisher's exact test) with Graphpad Prism 5.0. Probability values of 0.05 or less were considered significant.

\section{Results}

We showed that undergraduate students of the graduation pharmacy school that performed an integrative activity based on clinical practices, using a PBL methodology, did not have their evasion of the basic disciplines, Pharmacokinetics and Pharmacodynamics (Figure 1A) and Hospital Pharmacy (Figure 1B), significantly modified when compared to conventional methodology. The percentage of presence of students in the second evaluation in the discipline of Pharmacokinetics and Pharmacodynamics was $87 \%$ from conventional methodology to $90 \%$ in PBL methodology; while in the discipline of Hospital Pharmacy was $79 \%$ from conventional methodology to $82 \%$ in PBL methodology.

Nevertheless, in most health care disciplines of the graduation pharmacy school, we noted a significant reduction in the evasion of undergraduate students that performed an integrative activity based on clinical practices compared to students that did conventional methodology, including Pharmacology I (Figure 2A), Pharmacology II (Figure 2B), and Toxicology (Figure 2C). The only discipline in the health care curriculum in which the PBL methodology did not significantly alter the evasion of students was Clinical Pharmacy (Figure 2D). The percentage of presence of students in the second evaluation in the disciplines of Pharmacology I, Pharmacology II, Toxicology, and Clinical Pharmacy was $80 \%, 87 \%$, $92 \%$, and $92 \%$ from conventional methodology to $90 \%, 95 \%, 98 \%$, and $88 \%$ in PBL methodology, respectively.
Figure 1. The integrative activity based on clinical practices did not alter the school evasion of undergraduate students attending disciplines of basic curriculum in a pharmacy course.
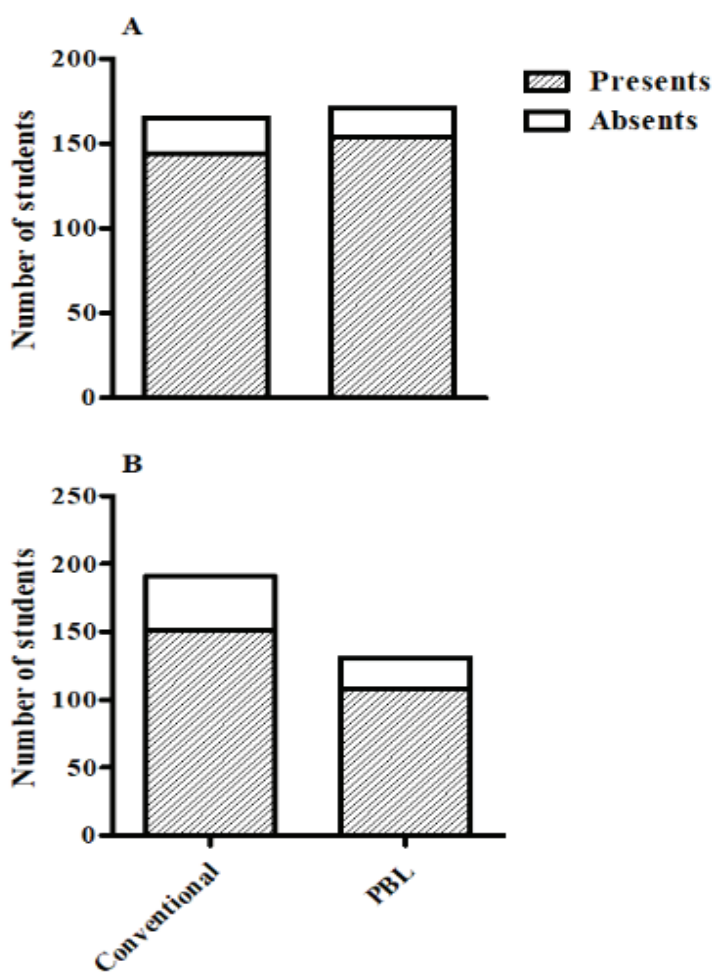

The graphics express the number of students present and absent in the second evaluation of the disciplines Pharmacokinetics and Pharmacodynamics (A) and Hospital Pharmacy (B).

Figure 2. The integrative activity based on clinical practices decreases the school evasion of undergraduate students attending disciplines of health care curriculum in a pharmacy course.
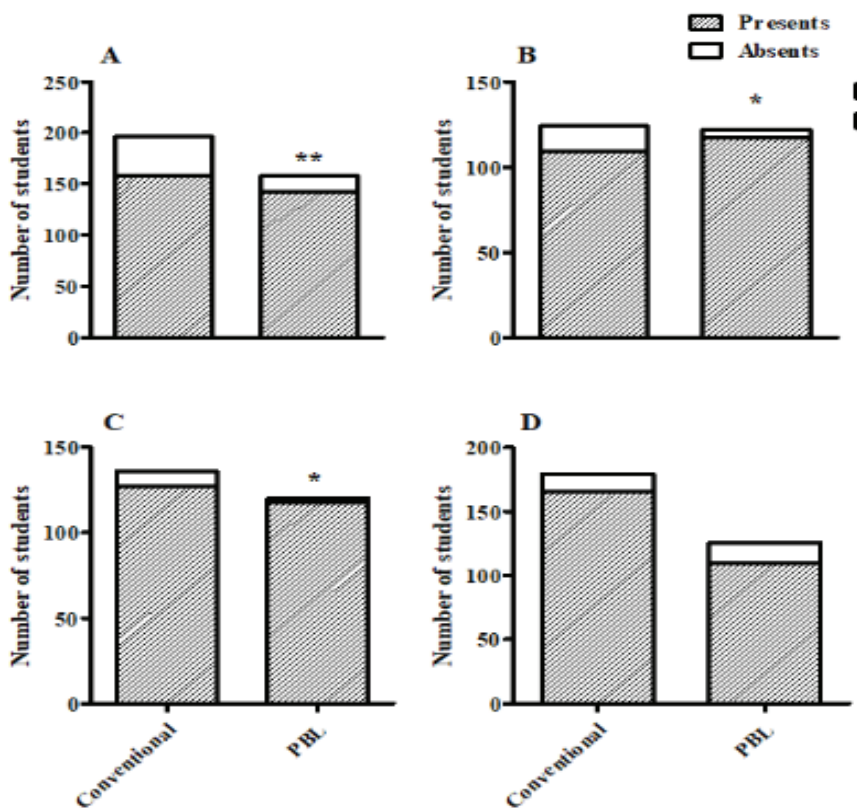

The graphics express the number of students present and absent in the second evaluation of the disciplines Pharmacology I (A), Pharmacology II (B), Toxicology (C) and Clinical Pharmacy (D).

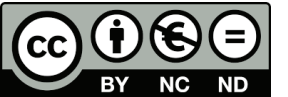


We observed that undergraduate students of the graduation pharmacy school that performed an integrative activity based on clinical practices increased significantly the school performance in the disciplines Hospital Pharmacy (Figure 3B), Pharmacology II (Figure 4B), Toxicology (Figure 4C), and Clinical Pharmacy (Figure 4D). However, this PBL methodology did not alter significantly the school performance in the discipline of Pharmacokinetics and Pharmacodynamics (Figure 3A) and reduced in the discipline of Pharmacology I (Figure 4A). The percentage of approval of students in the disciplines of Pharmacokinetics and Pharmacodynamics, Hospital Pharmacy, Pharmacology I, Pharmacology II, Toxicology, and Clinical Pharmacy was $60 \%, 54 \%, 58 \%, 71 \%, 68 \%$, and $72 \%$ from conventional methodology to $54 \%, 64 \%, 48 \%, 82 \%, 80 \%$, and $83 \%$ in PBL methodology, respectively.

Figure 3. The integrative activity based on clinical practices improves the school performance of undergraduate students attending disciplines of basic curriculum in a pharmacy course.
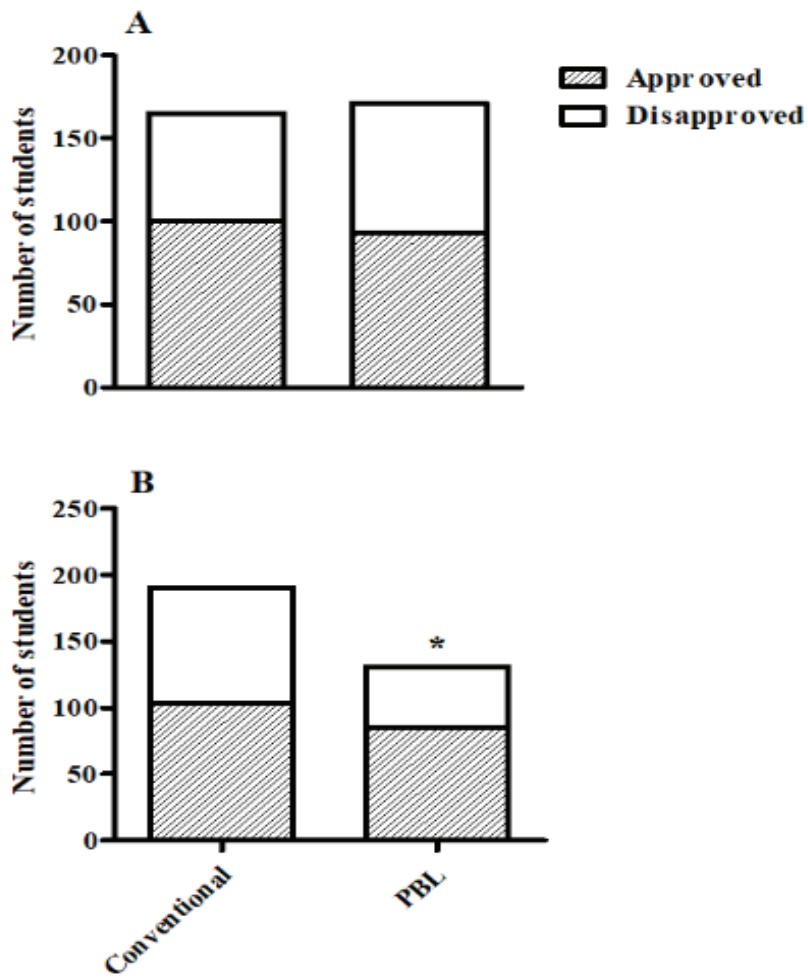

The graphics express the number of students approved and disapproved in the disciplines Pharmacokinetics and Pharmacodynamics (A) and Hospital Pharmacy (B).

\section{Discussion}

PBL was developed and used for the first time at McMaster University in Canada in the mid-1960s, ${ }^{17}$ using clinical problems or cases to stimulate the medical students to construct the most appropriate solution. Currently, the PBL teaching method is used in medical school worldwide; in addition, some medical schools have converted its curriculum exclusively in PBL. ${ }^{18}$ In the past few decades, some PBL sessions have been introduced into several schools of pharmacy as an adjunct and/or alternative to an orthodox didactic classroom-based model teaching in several countries. ${ }^{19-24}$ In the present study, we developed an
Figure 4. The integrative activity based on clinical practices increases the school performance of undergraduate students attending disciplines of health care curriculum in a pharmacy course.
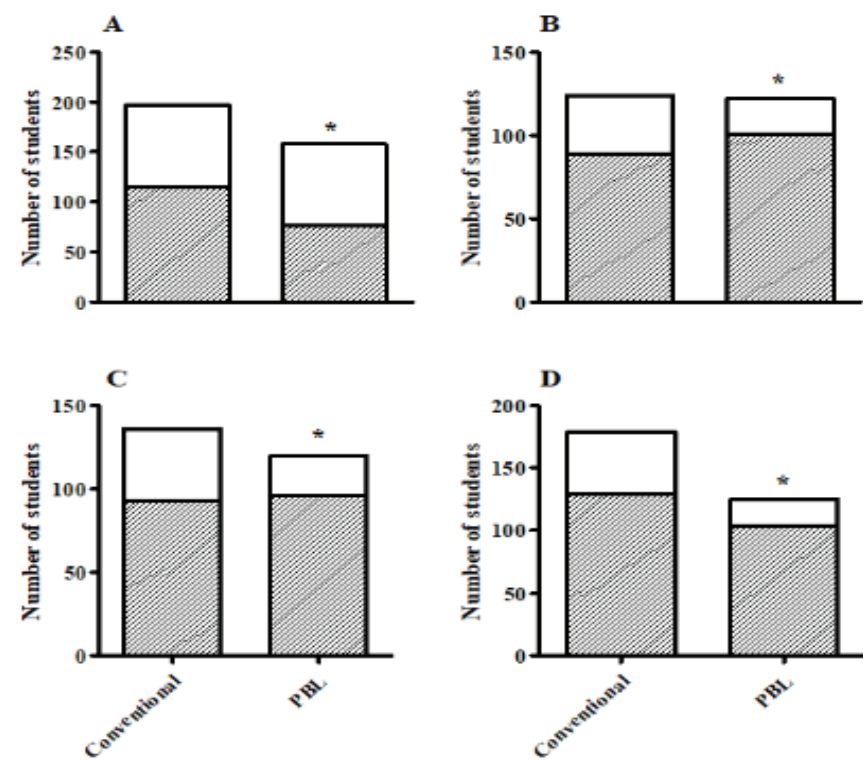

The graphics express the number of students approved and disapproved in the disciplines Pharmacology I (A), Pharmacology II (B), Toxicology (C) and Clinical Pharmacy (D).

interdisciplinary and integrative activity involving basic and health care disciplines focused on hospital pharmacy practice and applied to undergraduate pharmacy students. The goal of this approach was introduced highlights generic aspects of drug use in the intermediary years of the course, providing both horizontal and vertical integration and not only at the end of the course in a cumulative and horizontal way, as observed in conventional education. ${ }^{6}$ In this study, we carried out a comparison between an orthodox and a PBL teaching method applied to undergraduate pharmacist students in one University of Rio de Janeiro, Brazil. For this, we developed an integrative activity based on clinical practices and, then, apply this method in disciplines of the basic and health care curriculum focused on hospital pharmacy practice of pharmacy school.

We chose to include the following thematic axes in the integrative activity that was applied to undergraduate pharmacy students: patient and pharmaceutical care, including in special groups such as elderly, newborns, pediatric and pregnant patients. The choice of these axes was because they are current problems of high interest to the students, and that allows them to apply their knowledge and skills in the prescriptions analysis and drug dispensing even at the intermediary years of the course. One huge advantage of the discussion of the thematic axes was that the study of patient and pharmaceutical care in these special groups are not approached or are abbreviated in a very superficial way in the programmatic content of most Brazilian pharmacy school. Thus, the use of this methodology proposed that students could develop skills in this class of patients of great importance in clinical practice.

Then, the teaching methodology using these thematic axes also allowed us to apply the eight steps of PBL used in Manchester, ${ }^{25}$ which was a modified version of the "seven-jump" process from the medical school in Maastricht. ${ }^{26}$ These steps are: i) use of clear terms; ii) definition of questions or problems to be discussed. 
iii) provoking a brainstorm; iv) organization of explanations; v) definition of learning objectives; vi) research; vii) sharing of results of private study; viii) discussion of clinical experience. The choice of the use of the integrative methodology based on clinical practices in the basic and health care disciplines focused on hospital pharmacy practice was because we believe that there would be a greater interest of the students. In addition, the use of the integrative activity in this set of disciplines would provide students with a better vision and development of skills in critical thinking, problem-solving and decision making in complications associated to hospital pharmacy practice, including prescriptions analysis and drug dispensing, besides pharmacotherapeutic guidance and monitoring.

After applied our integrative activity, we noted that the avoidance of disciplines Pharmacology I, Pharmacology II, and Toxicology reduced significantly compared to conventional teaching method. These data are very interesting because they show that, in these disciplines of health care, the integrative methodology was able to increase students' interest in keeping absorbing the new knowledge with a bias towards clinical practice. However, the evasion of the disciplines of the basic curriculum, Pharmacokinetics and Pharmacodynamics and Hospital Pharmacy, greatly reduced although it was not significant. A possible explanation for not reducing the percentage of avoidance in these disciplines is that as they are attending basic disciplines, a significant part of the students did not perceive the difference that the new teaching tool used could have an impact on the development of the perception of the knowledge addressed at the beginning of the course. Regarding the discipline Clinical Pharmacy, the nonchange in avoidance can be explained by the low percentage of evasion already in conventional teaching methodology, probably because it is a discipline with a very clear clinical practice in its basic curriculum.

In addition, we observed that the students that who participated in the integrative activity in the disciplines Hospital Pharmacy, Pharmacology II, Toxicology, and Clinical Pharmacy improved significantly the school performance compared to academics who studied only with the conventional teaching method. These data suggest that the PBL teaching method used for us was able to increase the students' learning ability in these disciplines. However, this integrative activity did not alter significantly the school performance in the discipline of Pharmacokinetics and Pharmacodynamics, probably because it is a discipline of the basic curriculum of the pharmacy school. Finally, we observed that after applied the PBL teaching method, the students presented a significant decrease in the school performance in the discipline Pharmacology I. Although we do not have an explanation for this, we believe that it does not invalidate the outcome of the PBL teaching methodology applied by us, since we observed a reduction in avoidance and increased school performance in most of the disciplines evaluated, especially those of the health care curriculum focused on hospital pharmacy practice.

Although our data are extremely interesting and encouraging, we cannot fail to mention some limitations of our study. The most limitation is that we did not perform a qualitative study about the perception of learning of our students. With this, we can claim that our students presented a better academic performance with the use of the integrative activity, but not that they presented a greater perception of learning. Furthermore, we cannot infer that this improvement in academic performance of our students that participated of PBL teaching method results in better professionals, once the proposed benefits of introducing this integrative activity based on clinical practices into the undergraduate pharmacy curriculum have not yet been verified. Future study is design to evaluate some of these outcomes in pharmacy graduates to identify whether the proposed benefits are performed in practice.

\section{Conclusion}

This study showed that the integrative activity based on clinical practices was an appropriate teaching method for the introduction of patient and pharmaceutical cares, including in special groups such as elderly, newborns, pediatric and pregnant patients, at the Pharmacy School at the UNISUAM at Rio de Janeiro, Brazil. We described a PBL teaching method that can be used in both small and large classroom setting to instruct basic and health care disciplines focused on hospital pharmacy practice without the need for additional tutors. Our data also showed that combined use of PBL teaching method in addition to conventional didactic lectures avoided student dropout in association with an improve in academic performance, especially in health care disciplines focused on hospital pharmacy practice. After the development of this work, we are motivated to continue to refine the course delivery method, the research techniques and methodologies used to assess its outcomes, and, most importantly, attempt to measure improvements in student learning and retention of information because of the PBL teaching methodology.

\section{Funding sources}

We did not receive funding for its completion.

\section{Collaborators}

FAFF; LGSL; ROR; VFC: Project conception or analysis and interpretation of data; FAFF; VFC: Article writing or critical review relevant to the intellectual content. All the authors must approve the final version to be published and be responsible for all information in the paper, ensuring the accuracy and integrity of any part of it.

\section{Conflict of interests' statement}

The authors declare that there are no conflicts of interest regarding this article.

\section{References}

1. Woodman OL, Dodds AE, Frauman AG, et al. Teaching pharmacology to medical students in an integrated problem-based learning curriculum: an Australian perspective. Acta Pharmacol Sin. 2004; 25(19): 1195-1203.

2. Ross S, Maxwell S. Prescribing and the core curriculum for tomorrow's doctors: BPS curriculum in clinical pharmacology and prescribing for medical students. $\mathrm{Br} \mathrm{J}$ Clin Pharmacol. 2012; 74(4): 644-661.

3. Machado APC, Tomich CSF, Osme SF, et al. Prescribing errors 
in a Brazilian neonatal intensive care unit. Cad Saude Publica. 2015; 31(12): 2610-2620.

4. Mori ALPM, Carvalho RC, Aguiar PM, et al. Potentially inappropriate prescribing and associated factors in elderly patients at hospital discharge in Brazil: a cross-sectional study. Int J Clin Pharm. 2017; 39(2): 386-393.

5. Ryan C, Ross S, Davey $P$, et al. Prevalence and causes of prescribing errors: the PRescribing Outcomes for Trainee Doctors Engaged in Clinical Training (PROTECT) Study. Plos One. 2014; 9(1): e79802.

6. Maxwell S, Walley T. Teaching safe and effective prescribing in UK medical schools: a core curriculum for tomorrow's doctors. Br J Clin Pharmacol. 2003; 55(6): 469-503.

7. Sosabowski MH, Gard PR. Pharmacy education in the United Kingdom. Am J Pharm Educ. 2008; 72(6): article 130.

8. Maxwell SRJ, Coleman JJ, Bollington L, et al. Prescribing Safety Assessment 2016: Delivery of a national prescribing assessment to 7343 UK final-year medical students. Br J Clin Pharmacol. 2017; 83(10): 2249-2258.

9. Klegeris A, Hurren H. Impact of problem-based learning in a large classroom setting: student perception and problem-solving skills. Adv Physiol Educ. 2011; 35(4): 408-415.

10. Wichadee S, Orawiwatnakul W. Cooperative Language Learning: Increasing Opportunities For Learning In Teams. Journal of College Teaching \& Learning. 2012; 9(2): 93-100.

11. Laal M. Positive interdependence in collaborative learning. Procedia Soc Behav Sci. 2013; 93: 1433-1437.

12. Hintz MM. Can problem-based learning address content and process? Biochem Mol Biol Educ. 2005; 33(5): 363-368.

13. Schwartz PL. Active, small group learning with a large group in a lecture theatre: a practical example. Med Teach. 1989; 11(1): 81-86.

14. Rangachari PK. Design of a problem-based undergraduate course in pharmacology: implications for the teaching of physiology. Adv Physiol Educ. 1991; 260(6): S14-21.

15. Woods DR. Problem-based learning for large classes in chemical engineering. New Dir Teach Learn. 1996; 1996(68): 91-99.

16. Pastirik PJ. Using problem-based learning in a large classroom. Nurse Educ Pract. 2006. 6(5): 261-267.

17. Barrows HS, Tamblyn RM. Problem-based learning: An approach to medical education. New York. 1st Edition. Springer Publishing Company, 1980.

18. Wood D. ABC of learning and teaching in medicine. BMJ. 2003; 326(7384): 328-330.

19. Haworth IS, Eriksen SP, Chmait SH, et al. A problem based learning, case study approach to pharmaceutics: faculty and student perspectives. Am J Pharm Educ. 1998; 62(4): 398405.

20. Borrego ME, Rhyne R, Hansbarger LC. Pharmacy student participation in rural interdisciplinary education using problem based learning (PBL) case tutorials. Am J Pharm Educ. 2000; 64(4): 355-363.
21. Caldwell NA, Sexton JA, Green CF, et al. Sowing the seeds for pharmaceutical care: developments in undergraduate clinical teaching at Liverpool school of pharmacy. Pharm J. 2001; 267: 721-723.

22. Connelly D. Integrating practice and science is central to new course at East Anglia. Pharm J. 2004; 272: 130.

23. Romero RM, Eriksen SP, Haworth IS. A decade of teaching pharmaceutics using case studies and problem-based learning. Am J Pharm Educ. 2004; 68(2): article 31.

24. Novak S, Shah S, Wilson JP, et al. Pharmacy students' learning styles before and after a Problem-based learning experience. Am J Pharm Educ. 2006; 70(4): article 74.

25. O'Neill PA. Problem-based learning alongside clinical experience: reform of the Manchester curriculum. Educ Health. 1998; 11(1): 37-48.

26. Schimidt HG. Problem-based learning: rationale and description. Med Educ. 1983; 17(1): 11-16. 
Supplementary Table 1. Pharmacy School of UNISUAM Program Outline

\begin{tabular}{|c|c|c|}
\hline Year & Course Title & Credits $^{\mathrm{a}}$ \\
\hline \multirow[t]{3}{*}{1} & Morphology Sciences & 8 \\
\hline & Cellular and Molecular Biology & 4 \\
\hline & Fundamental Chemical and Molecular Sciences & 12 \\
\hline \multirow[t]{5}{*}{2} & Analytical Chemistry & 8 \\
\hline & Organic Chemistry & 8 \\
\hline & Psychology & 2 \\
\hline & Basic Microbiology and Immunology & 4 \\
\hline & Hospital Pharmacy & 2 \\
\hline \multirow[t]{4}{*}{3} & Basic Biochemistry, Parasitology, Pathology and Physiology & 20 \\
\hline & Pharmacokinetics and Pharmacodynamics & 2 \\
\hline & Pharmacotecnie & 4 \\
\hline & Bromatology & 4 \\
\hline \multirow[t]{7}{*}{4} & Applied Pharmacology & 8 \\
\hline & Clinical Pharmacy & 4 \\
\hline & Medicinal Chemistry & 4 \\
\hline & Pharmaceutical Ethics, Management and Administration & 4 \\
\hline & Therapeutic Aspects of Natural Products and Pharmacognosy & 8 \\
\hline & Homeopathy & 4 \\
\hline & Pharmaceutical Biochemistry, Hematology, Immunology, Microbiology and Parasitology & 20 \\
\hline \multirow[t]{4}{*}{5} & Project (including experimental design \& analysis) & 5 \\
\hline & Toxicology & 4 \\
\hline & Industry Pharmacy & 8 \\
\hline & Practical Pharmaceutical Skills in Community Pharmacy, Hospital Pharmacy, Industry Pharmacy and Clinical Analysis & 44 \\
\hline
\end{tabular}

a1 credit $=20$ hours of study

Supplementary Table 2. Studied content in the basic and health care disciplines of hospital pharmacy practice

\begin{tabular}{|c|c|}
\hline Course Title & Studied Content \\
\hline \multirow{5}{*}{$\begin{array}{l}\text { Pharmacokinetics and } \\
\text { Pharmacodynamics }\end{array}$} & The mechanisms of drug absorption, distribution, metabolism and excretion; \\
\hline & The concepts of volume of distribution, clearance and half-life; \\
\hline & Factors that determine variation in drug response; \\
\hline & Pharmacokinetic handling of drugs; \\
\hline & The receptor as a target of drug action and related concepts such as agonism, antagonism, partial agonism and selectivity. \\
\hline \multirow[t]{4}{*}{ Hospital Pharmacy } & Management and administration of hospital pharmacy; \\
\hline & Drugs selection and distribution systems; \\
\hline & Hospital pharmacy legislation; \\
\hline & Pharmacovigilance. \\
\hline \multirow[t]{3}{*}{ Pharmacology I } & Pharmacology of autonomous and central nervous systems; \\
\hline & Pharmacology of cardiovascular and renal systems; \\
\hline & Pharmacology of blood diseases. \\
\hline \multirow[t]{5}{*}{ Pharmacology II } & Pharmacology of inflammation and allergic diseases; \\
\hline & Pharmacology of lung system; \\
\hline & Pharmacology of gastrointestinal systems; \\
\hline & Pharmacology of endocrine system; \\
\hline & Pharmacology of antimicrobial agents and antineoplastic drugs. \\
\hline \multirow[t]{5}{*}{ Toxicology } & Drug toxicity; \\
\hline & Toxicological indicators and markers; \\
\hline & Physicochemical properties of toxic agents; \\
\hline & Occupational and environment toxicity; \\
\hline & Toxicological analyzes. \\
\hline \multirow[t]{5}{*}{ Clinical Pharmacy } & Prescriptions analysis and drug dispensing; \\
\hline & Pharmacotherapeutic follow-up; \\
\hline & Algorithms and triggers used for identification of adverse reaction to drugs; \\
\hline & Drug use studies; \\
\hline & Promotion of the rational use of drugs for therapeutic purposes. \\
\hline
\end{tabular}


Supplementary Figure 1. Studied content in the basic and health care disciplines of hospital pharmacy practice

\section{Step}

tep I: The introduction to the lesson

Step 2: The activities

Step 2.2: The cooperative problembased learning activities to enhance cooperation skill

Step 3: The conclusion of lesson
Sub-Step

Learning Method/Tools
Professor explains the purpose of the

Professor organizes students into small groups of 5-6 people per group

Professor suggests how to work in groups,

the role of leader and members, and criteria for determining the works learning activity $\rightarrow$ Professor explains learning objective

Professor organizes students into small groups of 5-6 people per group, and the group choose a person to be the leader $\rightarrow \begin{aligned} & \text { Professor suggests how to work in groups, and the } \\ & \text { role of leader and members in the learning method }\end{aligned}$

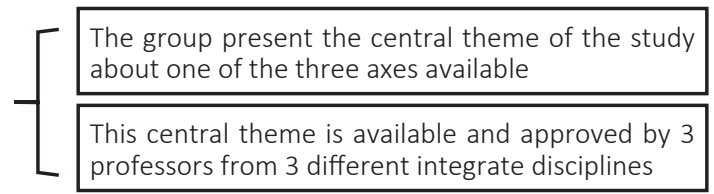
professors from 3 different integrate disciplines

Learners study and understand the problem by

Understanding the problem $\rightarrow \rightarrow \begin{aligned} & \text { Learners study and understand the problem by } \\ & \text { discussion through online communication channels, } \\ & \text { group }\end{aligned}$

Understanding the problem $\rightarrow \rightarrow \begin{aligned} & \text { learners study and understand the problem by } \\ & \text { discussion through online communication channels, } \\ & \text { group chat, and document sharing }\end{aligned}$

Professor provides learning materials hypothesis, and objectives through presential meetings, group chat, and via University on-line channels andrecommends resources on the internet knowledge

\section{Learners cooperate to define the problem,} assumptions, and objectives

The group search the related data and scaffolding
Learners brainstorm and discuss issues, hypothesis, and objectives through document sharing presential meetings, group chat, and document sharing

Learners search related data from the internet, library, and document sharing.

Learners help each other during cooperative problem solving in presential meetings and group chat

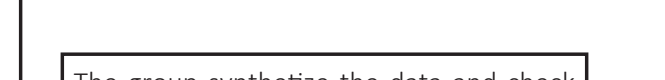

The group synthetize the data and check assumptions

Brainstorm and discussion to synthetize information for use in problem solving and hypothesis test through presential meetings and group chat

Professors monitor learners behavior, including providing advice and suggestions

Professors observe and given advice in the presential meetings

Evaluation of the project by the professors

The fina I project prepared by the group is evaluated by tlu-ee professors

Professor and learners share lessons and ideas to improve learning goals

Professor and learners share lessons and ideas in presential meetings

Presentation of project to the class and sharing ideas with this large group of learners

Working group evaluation and testing
Presentation of project in an event dedicated to the local community and evaluation of the project's receptivity by professors 